\title{
Entropy Base Estimation of Moisture Content of the Top 10-m Unsaturated Soil for the Badain Jaran Desert in Northwestern China
}

\author{
Xiangyang Zhou ${ }^{1}$, Wenjuan Lei ${ }^{2, *}$ and Jinzhu $\mathrm{Ma}^{3}$ \\ 1 State Key Laboratory of Hydraulics and Mountain River Engineering, Sichuan University, \\ Chengdu 610065, China; zhouxylzu@163.com \\ 2 College of Architecture \& Environment, Sichuan University, Chengdu 610065, China \\ 3 Key Laboratory of Western China's Environmental Systems, Ministry of Education (MOE), \\ Lanzhou University, Lanzhou 730000, China; jzma@lzu.edu.cn \\ * Correspondence: leiwenjuan@scu.edu.cn; Tel.: +86-177-2331-6606 \\ Academic Editor: Raúl Alcaraz Martínez \\ Received: 12 July 2016; Accepted: 31 August 2016; Published: 3 September 2016
}

\begin{abstract}
Estimation of soil moisture distribution in desert regions is challenged by the deep unsaturated zone and the extreme natural environment. In this study, an entropy-based method, consisting of information entropy, principle of maximum entropy (PME), solutions to PME with constraints, and the determination of parameters, is used to estimate the soil moisture distribution in the $10 \mathrm{~m}$ deep vadose zone of a desert region. Firstly, the soil moisture distribution is described as a scaled probability density function (PDF), which is solved by PME with the constraints of normalization, known arithmetic mean and geometric mean, and the solution is the general form of gamma distribution. A constant arithmetic mean is determined by considering the stable average recharge rate at thousand year scale, and an approximate constant geometric mean is determined by the low flow rate (about $1 \mathrm{~cm}$ a year). Followed, the parameters of the scaled PDF of gamma distribution are determined by local environmental factors like terrain and vegetation: the multivariate linear equations are established to qualify the relationship between the parameters and the environmental factors on the basis of nineteen random soil moisture profiles about depth through the application of fuzzy mathematics. Finally, the accuracy is tested using correlation coefficient (CC) and relative error. This method performs with CC larger than 0.9 in more than a half profiles and most larger than 0.8 , the relative errors are less than $30 \%$ in most of soil moisture profiles and can be as low as less than $15 \%$ when parameters fitted appropriately. Therefore, this study provides an alternative method to estimate soil moisture distribution in top 0-10 m layers of the Badain Jaran Desert based on local terrain and vegetation factors instead of drilling sand samples, this method would be useful in desert regions with extreme natural conditions since these environmental factors can be obtained by remote sensing data. Meanwhile, we should bear in mind that this method is challenged in humid regions since more intensive and frequent precipitation, and more vegetation cover make the system much more complex.
\end{abstract}

Keywords: soil moisture distribution; principle of maximum entropy; information entropy; deep vadose zone; Badain Jaran Desert

\section{Introduction}

Soil moisture is a crucial factor in hydrologic, geomorphic, and pedogenic processes [1,2]. Moreover, it influences the partition of available energy between latent and sensible heat, and the magnitude of the net radiation absorption by the soil surface [3]. Under extremely dry conditions, both the number and the size of perennial plant species are limited by the availability of soil water $[4,5]$. 
Hence, it is necessary to know the soil moisture content in desert regions. A wide range of methods are used to measure the soil moisture, including mass soil water content by the drying method, volume moisture content by neutron probes, TDR probes, and remote sensing. However, these methods are challenged by the measurement of soil moisture in deep desert vadose zones. Soil moisture estimates are obtained within the top $5 \mathrm{~cm}$ depth by passive remote sensing [6] and at greater depths by active sensors, and a depth of tens of centimeters by TDR, whereas the depth of the vadose zone in desert regions is usually up to tens or hundreds of meters. The mass moisture content is limited by the huge amount of work as well as difficult natural conditions.

In recent years, entropy-based methods were used to estimate soil moisture in the vadose zone. Information content and complexity were used in soil water fluxes simulation [7]. Al-Hamdan and Cruise estimated the soil moisture profile to near $50 \mathrm{~cm}$ on the basis of PME [8]. Some infiltration equations were derived based on the principle of maximum entropy (PME) with the Shannon entropy or information entropy [9] as well as soil moisture movement on the basis of PME with Tsallis entropy [10]. The soil moisture distribution was also estimated in an irrigated field in North Central Alabama, USA, based on the PME [11]. These studies assumed that the vertical soil moisture distribution curve is a scaled probability density function (PDF) that follows PME. Then the PDF was solved using Lagrange multipliers with constraints of normalization and known mean.

The soil water distribution in a vertical profile usually exhibits three phases, including just after rainfall (wet), a long time after rainfall (dry) and a short time after rainfall [9], which are illustrated in Figure 1a. However, some different characteristics were observed in the $10 \mathrm{~m}$ depth vadose zone of desert regions. Generally, the soil moisture profiles should be considered as the dry phase in desert areas as a result of the intense potential evaporation and little precipitation. Previous studies revealed that the distribution of soil moisture profiles have three subcategories in the deep vadose zone of the Badain Jaran Desert in Northeastern China, including an increase first then a decreasing trend, the increase then being stable and affected by ground water levels [12,13], as shown in Figure $1 \mathrm{~b}$.

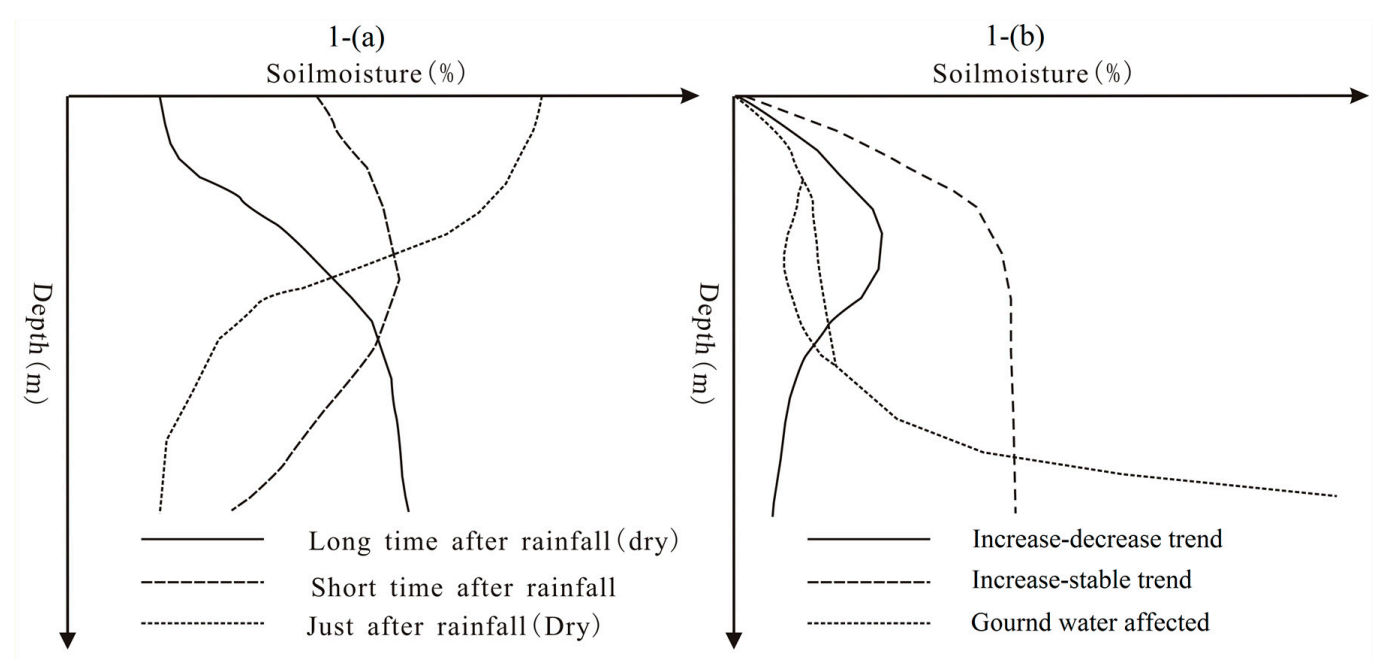

Figure 1. Illustration of moisture distributions in vadose zone (a) soil moisture profiles in shallow vadose zone [10]; (b) soil moisture profiles in deep vadose zone of Badain Jaran Desert [12].

The two former types are the typical moisture distribution in this region, corresponding to the distribution of a short time after rainfall and a long time after rainfall in the shallow soil layer, respectively. Therefore, these soil moisture distributions could be calculated by a method based on entropy theories. Singh considered the soil moisture distribution of a short time after rainfall (or lognormal distribution type) to consist of two parts: the dry case and the wet case [10]. This is only constrained by the limit of known information of the PDF (normalization and known mean) and the result is an exponential shaped curve. Further information is required to solve the soil moisture 
distribution curve similar to a two parameter probability distribution, such as gamma distribution, lognormal distribution and normal distribution. In desert regions, fortunately, the soil moisture distribution is a record of both precipitation and recharge history [14]. For example, a $10 \mathrm{~m}$ deep soil moisture profile is an archive of the climate change in the past 1000 years [15]. Hence, when sand texture and local environmental factors are determined, the total soil moisture in the deep vadose zone of the desert regions can be regarded as a constant since the difference between precipitation and evaporation is almost a constant on a thousand year scale. Apart from that, the geometric mean of the soil moisture curve is also a constant because the flow rate is extremely slow in desert regions. For example, the soil water recharge to ground water is about 1-1.3 mm per year in the Badian Jaran Desert [16]. Hence, the PDF-based distribution of soil moisture can be considered as a whole instead of two parts in this study area. Apart from that, soil moisture distribution is determined by the soil texture, local environmental factors like terrain and vegetation, and climatic factors [17]. In the deep desert vadose zone region, the texture is determined by the sand deposition and can be considered as constant at a small spatial scale; the vegetation is constricted by the soil moisture content in the top ten meters even as deep as dozens of meters, the climatic conditions are relatively uniform and is mostly affected by the terrain. Hence the system controlling soil moisture in desert regions is simpler than systems in humid regions, and establishing the relationship between soil moisture distribution and local surface controlling factors should be easier to achieve. A good correlation between the soil moisture distribution and local terrain and vegetation was revealed by geo-statistical analysis in the Badain Jara Desert [12,13].

Therefore, the objectives of this study are to: (1) consider the soil moisture distribution as an scaled entire probability distribution instead of two part in the deep vadose zone of the Badain Jaran Desert, and solve the distribution on the basis of PME with the constraints of normalization, known arithmetic mean and geometric mean; (2) determine the parameters of the scaled PDF based on local land surface factors like terrain and vegetation through the application of fuzzy mathematics methods, and to test the performance of this entropy-based method.

\section{Study Area}

The Badain Jaran Desert is located in the northwestern part of the Alashan Plateau of western Inner Mongolia $\left(39^{\circ} 20^{\prime} \mathrm{N}\right.$ to $41^{\circ} 30^{\prime} \mathrm{N}$ and $100^{\circ} \mathrm{E}$ to $104^{\circ} \mathrm{E}$; Figure 2), and covers an area of some $49,000 \mathrm{~km}^{2}$ [18]. It contains the third largest dune field in China, and includes the highest megadunes on Earth. The dunes are interspersed with lakes that occur in many low-lying areas throughout the desert and that vary in size, shape, and salinity. From southeast to northwest the elevation gradually decreases from approximately $1800 \mathrm{~m}$ asl to $1000 \mathrm{~m}$ asl.

The climate in the Badain Jaran Desert is an extreme continental type, with hot summers and cold winters. Daily daytime temperatures in summer months range up to $40{ }^{\circ} \mathrm{C}$, while mean monthly temperatures fall to $-10^{\circ} \mathrm{C}$ in January, and sub-zero minimum temperatures prevail for most of the year. The southeastern Badain Jaran Desert is near the current northern extent of the East Asian monsoon, which provides the primary source of precipitation, $70 \%$ of which falls from July to September. Rain falls on 10-35 days per year. Cold and dry continental air masses from the prevailing westerly winds dominate the region in the winter. The mean annual precipitation measured at the meteorological station nearest to the present study area (Zhongqanzi Station, $20 \mathrm{~km}$ southeast of the study area) was $84 \mathrm{~mm}$ from 1956 to 1999 and was highly variable (coefficient of variation $=0.39$ ). In contrast, the potential evaporation from surface water is $2600 \mathrm{~mm} \cdot$ year $^{-1}$ [19]. Average precipitation decreases significantly from south to north, declining to about $50 \mathrm{~mm} \cdot \mathrm{year}^{-1}$ at Wentugaole, near the border between China and Mongolia [20], due to the progressively declining influence of monsoonal moisture. Orographic effects result in slightly higher rainfall rates in the Yabulai Mountains $\left(150 \mathrm{~mm} \cdot\right.$ year $\left.^{-1}\right)$ in the southeastern part of the desert. The mean annual wind speed ranges from 2.8 to $4.6 \mathrm{~m} \cdot \mathrm{s}^{-1}$, and increases from the south to the north, with the strongest winds in April and May. 


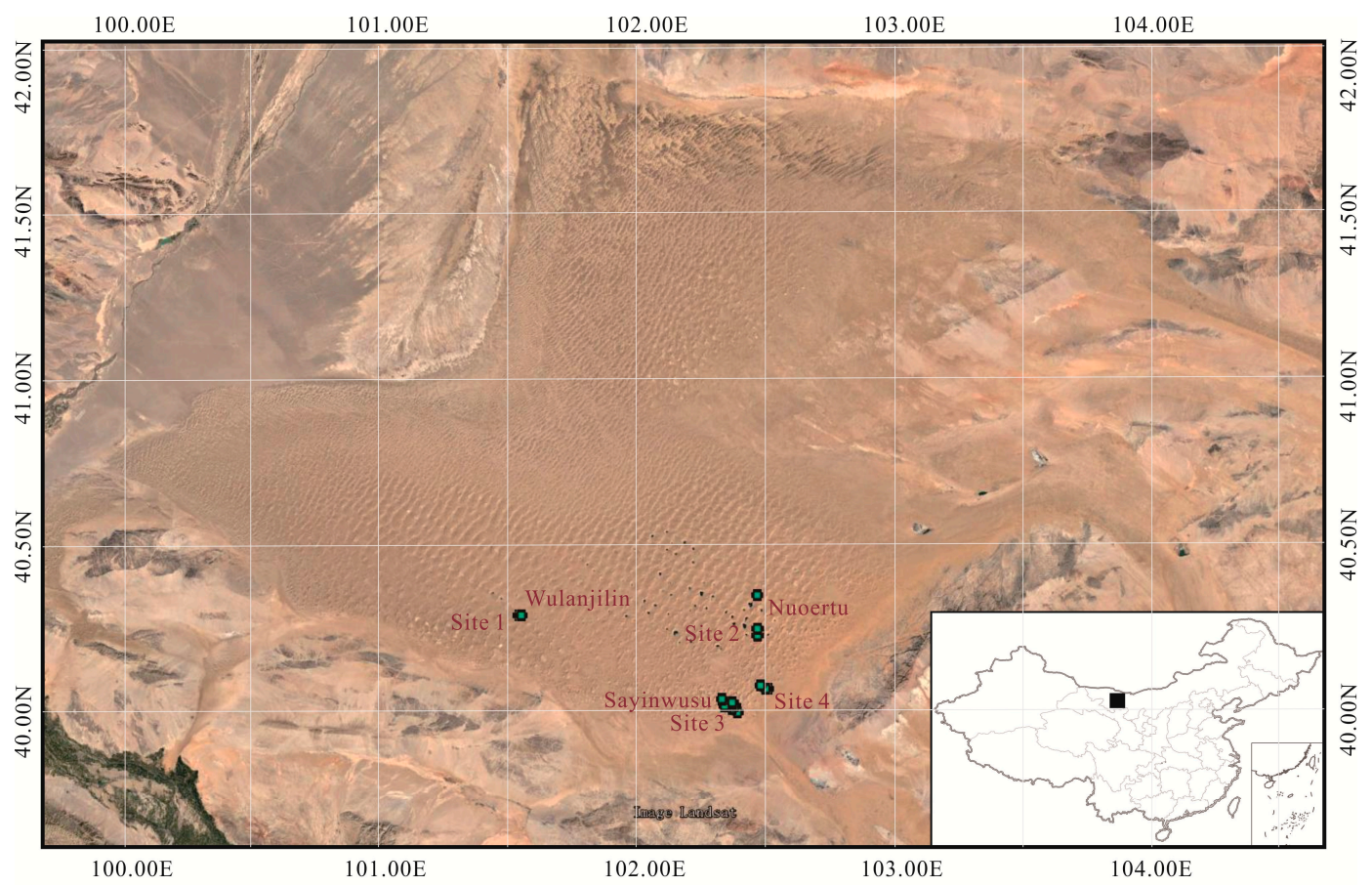

Figure 2. Location of the study area and spatial distribution of the sampling sites. Site 1, Wulanjilin; Site 2, Nuoertu; Site 3, Sayinwusu; Site 4, Baoritaolegai. The remote sense image is from Google earth, and the projection is WGS-1984 for the coordinates of sampling sites to keep the consistent with the Google earth.

\section{Maximum Information Entropy Theories}

\subsection{Information Entropy}

Information entropy or Shannon's entropy of a random variable $X$ with the $\operatorname{PDF} f(x)$ is defined as the negative expectation value of the logarithmic $f(x)$ [21], usually denoted as $H(x)$ :

$$
\begin{gathered}
H(x)=-\int_{a}^{b} f(x) \ln (f(x)) d x \\
\int_{a}^{b} f(x) d x=1
\end{gathered}
$$

where $a$ is the minimum of variable $X$ and $b$ is the maximum of variable $X$.

The entropy of a single discrete random variable $X$ is a measure of its average uncertainty, which is expressed by Equation (3):

$$
H(x)=-\sum_{i=1}^{n} p_{i} \ln \left(p_{i}\right)
$$

where $X$ represents a random variable with a set of values $i$ and probability mass function $p\left(x_{i}\right)=\operatorname{Pr}\left(X=x_{i}\right)$. Note that $p \log p=0$ if $p=0$.

\subsection{Principle of Maximum Entropy and Probability Distribution}

Principle of maximum entropy (PME) theory is used as a constructive criterion for setting up the least biased probability distribution based on partial knowledge [22,23]. If no other information is available except given statistical constraints, the distribution on the basis of PME is the least biased toward unavailable information. Therefore, the probability distributions are quite different with 
different constraints or known information. For the $\operatorname{PDF} f(x)$, the first constraint is the normalization, shown as Equation (2). Apart from that, the mean, variance or other information can be considered as known information for specific conditions. These constraints are denoted as $g_{i}(x)$, which can be expressed as follows:

$$
\int_{a}^{b} g_{i}(x) f(x) d x=G_{i}
$$

In order to solve $f(x)$ with constrains of Equations (2) and (4), one simple method is using Lagrange multipliers to solve it under extreme conditions. The Lagrange function $L$ can be defined as Equation (5):

$$
L=-\int_{a}^{b} f(x) \ln (f(x)) d x+\lambda_{0}\left(\int_{a}^{b} f(x) d x-1\right)+\sum_{i=1}^{n} \lambda_{i}\left(\int_{a}^{b} g_{i}(x) f(x) d x-G_{i}\right)
$$

where $\lambda_{0}, \lambda_{1}, \lambda_{2}, \ldots, \lambda_{n}$ are Lagrange multipliers. As the information entropy is the maximum value, the partial derivative function is equal to zero, as shown in Equations (6)-(8):

$$
\begin{gathered}
\frac{\partial L}{\partial f}=0 \\
-\ln (f(x))-1+\lambda_{0}+\sum_{i=1}^{n} \lambda_{i} g_{i}(x)=0 \\
f(x)=e^{-1+\lambda_{0}+\sum_{i=1}^{n} \lambda_{i} g_{i}(x)}
\end{gathered}
$$

Equation (8) is the general PDF of random variable $X$ solved by PME with the constraints of Equations (2) and (4). More details on the mathematical proof of the probability distribution based on PME can be found in Conrad [24].

\section{Principle of Maximum Entropy for Soil Moisture Distribution in Deep Desert vadose Zone}

The function between soil moisture and vertical soil depth can be written as:

$$
\theta_{\mathrm{Z}}=f(z)
$$

where $\theta_{Z}$ is the soil moisture at depth $z$.

The accumulation of soil water:

$$
\int_{0}^{Z} f(z) d z=C
$$

where $C$ is the total soil water in a profile. Equation (10) can also be transformed as:

$$
\int_{0}^{Z} \frac{1}{C} f(z) d z=1
$$

Hence the scaled vertical soil moisture distribution $f(z) / C$ can be considered as a PDF. The information entropy can be calculated as:

$$
\begin{gathered}
H=-\int_{0}^{Z} \frac{1}{C} f(z) \ln \frac{f(z)}{C} d z \\
H=-\frac{1}{C} \int_{0}^{Z} f(z) \ln f(z) d z+\frac{1}{C} \ln C
\end{gathered}
$$

As the soil water can be seen as in an equilibrium state, the function $f(z) / C$ obeys the principle of maximum entropy, and the constraints of $f(z) / C$ are: (1) the normalization; (2) arithmetic mean is 
given since the average recharge rate or the average recharge depth at millennium scale is a constant; (3) geometric mean can be considered as a constant since flow rate is get close to zero and the soil moisture also can be approximately considered as an equilibrium state in desert regions, which are shown in Equations (11), (14) and (15):

$$
\begin{gathered}
\int_{0}^{Z} \frac{z}{C} f(z) d z=\mu_{z} \\
\int_{0}^{Z} \frac{\ln (z)}{C} f(z) d z=v_{z}
\end{gathered}
$$

where $\mu_{z}$ and $v_{z}$ and are the arithmetic mean and geometric mean of soil moisture distribution, respectively. Then we construct the Lagrange function $L$ with the constraints of (11), (14) and (15):

$$
\begin{aligned}
L=-\frac{1}{C} \int_{0}^{Z} f(z) \ln f(z) d z+\frac{1}{C} \ln C & +\lambda_{0}\left(\int_{0}^{Z} \frac{1}{C} f(z) d z-1\right) \\
& +\lambda_{1}\left(\int_{0}^{Z} \frac{z}{C} f(z) d z-\mu_{z}\right)+\lambda_{2}\left(\int_{0}^{Z} \frac{\ln (z)}{C} f(z) d z-v_{z}\right)
\end{aligned}
$$

Let $\frac{\partial L}{\partial f_{z}}=0$, we can find the probability density function $f(z) / C$ :

$$
f(z) / C=e^{\lambda_{0}-1+\lambda_{1} z+\lambda_{2} \ln z}
$$

Substituting Equation (17) into Equations (11), (14) and (15), we can obtain the values of $\lambda_{0}, \lambda_{1}$, $\lambda_{2}$. Equation (17) can also be transformed as (18):

$$
f(z) / C=e^{\lambda_{0}-1} e^{\lambda_{1} z} z^{\lambda_{2}}
$$

Equation (18) is the general form of a Gamma distribution. The soil moisture distribution based on a scaled $\operatorname{PDF} f(z) / C$ with different parameters is shown in Figure 3.

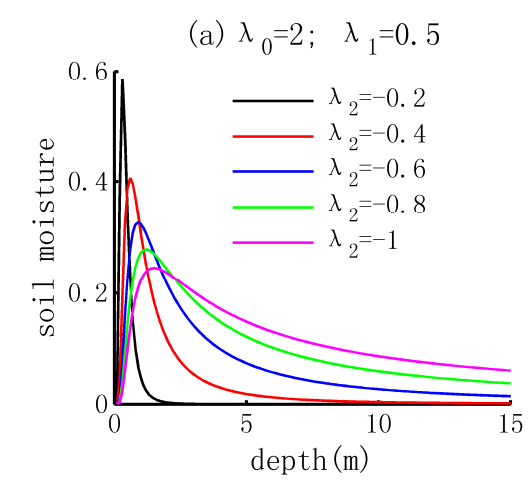

(c) $\lambda_{0}=2 ; \quad \lambda_{1}=1.5$

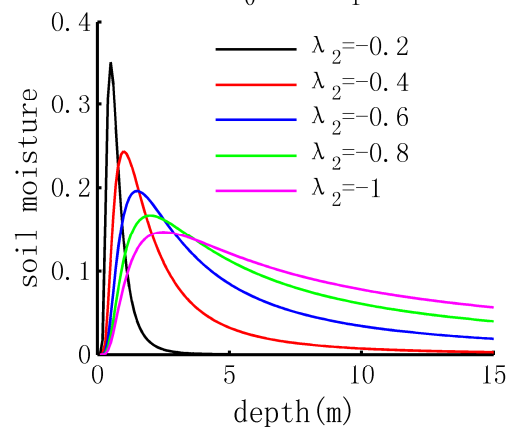

(b) $\lambda_{0}=2 ; \quad \lambda_{1}=1$

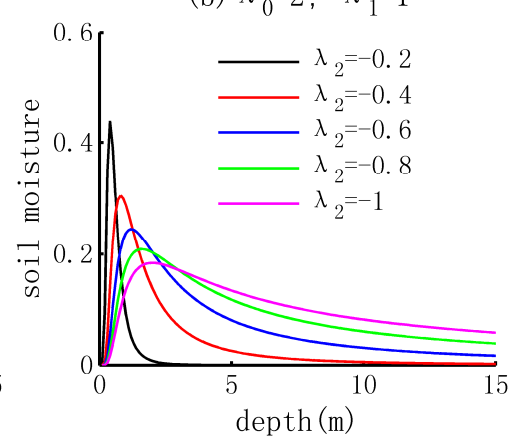

(d) $\lambda_{0}=2 ; \quad \lambda_{1}=2$

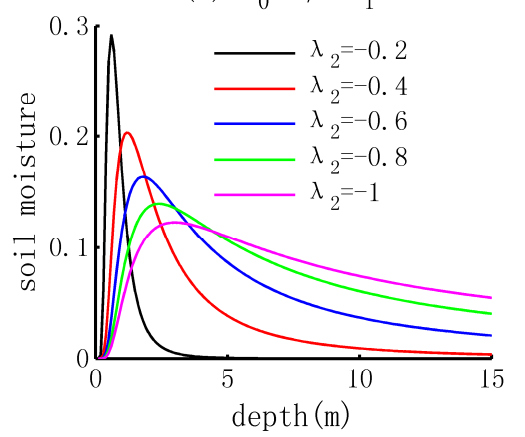

Figure 3. Illustration of soil moisture distribution based on a scaled PDF solved by PME with the constraints of normalization, known arithmetic mean and known geometric mean. 
In the Badain Jaran Desert, one centimeter depth sand profile usually records the archive of the recharge from precipitation in a year [15]. In other words, the average flow rate of soil movement is $1 \mathrm{~cm}$ per year. This indicates the shape of the soil moisture profile is almost the constant at the scale of decades of years, so the geometric mean of the profile can be considered as a constant. Meanwhile the arithmetic mean can also be considered as constant since the average recharge rate is a constant at one thousand year scale. Hence, the two constricts, both constant in arithmetic mean and geometric mean, are reasonable to determine the soil moisture distribution in desert region at the scale of a couple of decade years. The PDF of gamma distribution also displays the same pattern as the soil moisture profiles in desert regions, as shown in Figures 3 and 4, respectively.

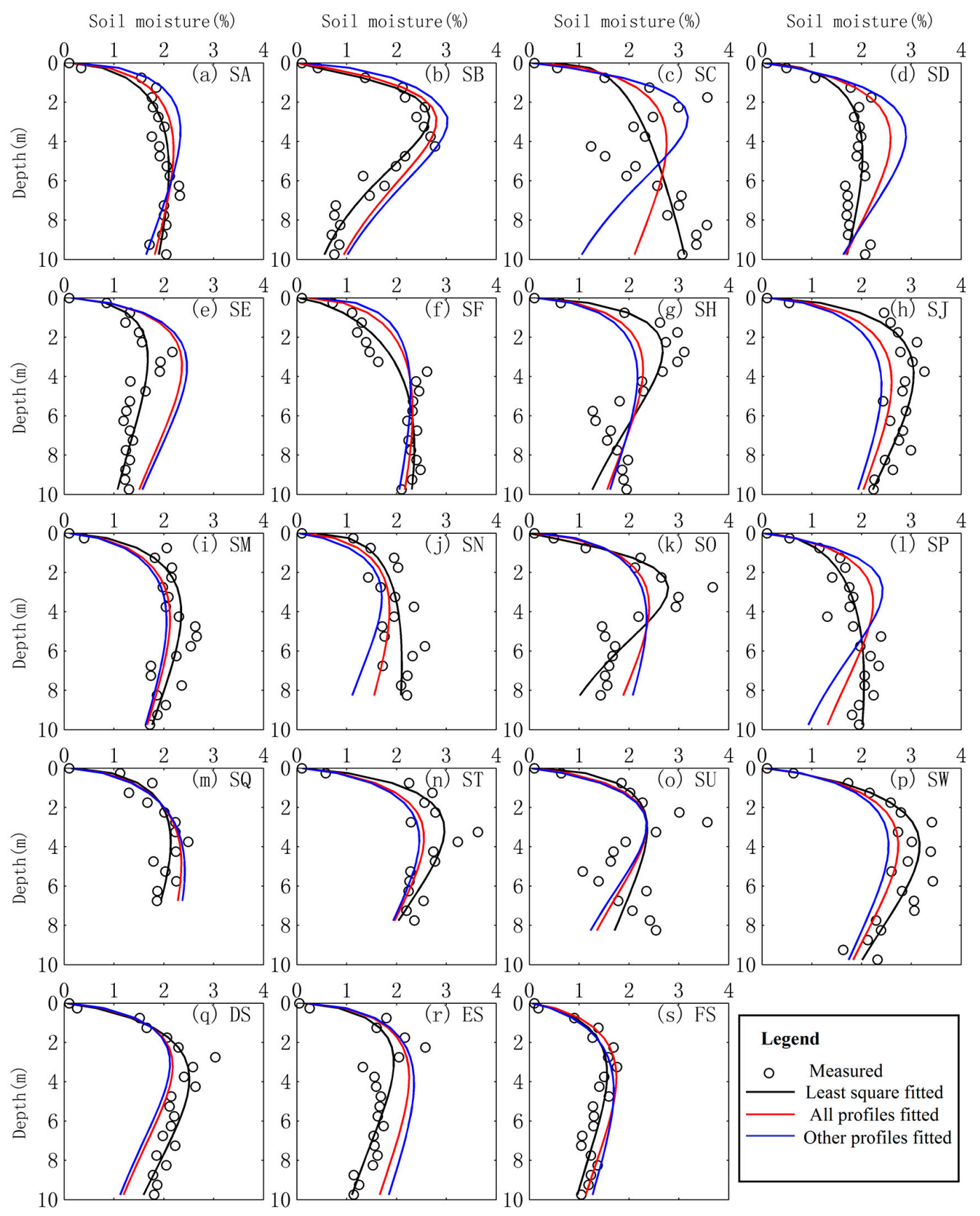

Figure 4. Measured and simulated soil moisture distributions in deep vadose zone of the Badain Jaran Desert. Cycles are the measured soil moisture content, black line is fitted by least square, red line is fitted by all 19 profiles and blue lines is fitted by the other 18 profiles. 


\section{Parameterization}

Actually, the soil moisture distribution is measured at a limit depth, which would lead to a substantial difference of the parameters (both arithmetic mean and geometric mean) between the real value and estimated value by samples, especially for the soil moisture distribution displaying the trend of increase then being stable. Even worse, both arithmetic mean and geometric mean are difficult to obtain at the depth of $10 \mathrm{~m}$ without drilling samples. Fortunately, previous studies showed that soil moisture distribution is correlated to local environmental factors in this region [12,13]. Therefore we can estimate the parameters based on the local environmental factors through the application of fuzzy mathematics method. In this study, multilinear equations are used to determine the parameters of the scaled PDF of gamma distribution.

\subsection{Soil Moisture Data}

Nineteen random deep soil moisture profiles are used to test the simulated results. Sand samples were collected from the southeastern part of the Badain Jaran Desert where dunes and lakes are densely interspersed (Figure 2) in June 2005 and September 2007. Samples in the unsaturated zone were obtained to a depth of about $10 \mathrm{~m}$ using a $50 \mathrm{~cm}$ hollow-stem hand auger (Dormer Engineering, Murwillumbah, Australia) with interchangeable $1.5 \mathrm{~m}$ aluminum rods. Bulk sediment samples of approximately $500 \mathrm{~g}$ were collected at intervals of $0.25 \mathrm{~m}$ in top $3 \mathrm{~m}$ and $0.50 \mathrm{~m}$ in 3-10 m respectively. Samples were homogenized over the sampled interval and immediately sealed in polyethylene bags, care being taken to avoid moisture loss. Locations and elevations were recorded with a Garmin GPS, as shown in Table 1. Moisture contents were determined gravimetrically after drying overnight at $110^{\circ} \mathrm{C}$. These data have been partly reported in the previous studies [12,13,19,25-27].

Table 1. Local environmental factors of typical random soil moisture profiles.

\begin{tabular}{cccccccc}
\hline ID & Depth & $\begin{array}{c}\text { Relative } \\
\text { Elev. }(\mathbf{m})\end{array}$ & $\begin{array}{c}\text { Distance to } \\
\text { Lake }(\mathbf{m})\end{array}$ & $\begin{array}{c}\text { Dry Layers } \\
\mathbf{( \mathbf { c m } )}\end{array}$ & $\begin{array}{c}\text { Slope } \\
\mathbf{(} \mathbf{(}^{\mathbf{n}}\end{array}$ & Orientation & Vegetation \\
\hline DS & 10.5 & 70 & 967 & 40 & 9 & $\mathrm{NW}$ & Sparse \\
ES & 10.5 & 25 & 1580 & 40 & 7 & $\mathrm{NW}$ & Sparse \\
FS & 10.5 & 176 & 1688 & 40 & 3 & $\mathrm{NW}$ & Sparse \\
SA & 13.5 & 18 & 251 & 40 & 5 & $\mathrm{NW}$ & Sparse \\
SB & 10 & 76 & 510 & 40 & 13 & SE & Sparse \\
SC & 10 & 24 & 513 & 60 & 0 & SW & Sparse \\
SD & 10 & 59 & 932 & 35 & 4 & S & Very sparse \\
SE & 10 & 22 & 944 & 40 & 6 & NE & None \\
SF & 10 & 32 & 2000 & 40 & 0 & NE & Sparse to moderate \\
SH & 10 & 21 & 1100 & 40 & 4 & N-NW & Sparse \\
SJ & 10 & 21 & 1400 & 40 & 5 & SW & Sparse \\
SM & 10 & 86 & 1600 & 40 & 0 & NE & Sparse \\
SN & 8.5 & 81 & 2600 & 30 & 12 & NW & Very sparse \\
SO & 10 & 21 & 1000 & 36 & 3 & NW & Very sparse \\
SP & 10 & 44 & 1300 & 23 & 8 & NW & Sparse \\
SQ & 8.65 & 44 & 1800 & 35 & 1 & W-NW & Sparse \\
SU & 9 & 32 & 354 & 45 & 1.5 & W-NW & Sparse \\
SV & 10 & 45 & 250 & 40 & 10 & NW & Sparse to moderate \\
SW & 10 & 39 & 500 & 40 & 0 & SE & Very sparse \\
\hline
\end{tabular}

\subsection{Data Preparation for Multiple Linear Regressions}

Before multiple linear regressions, the local terrain and vegetation data was encoded to qualify the data. For certain parameters, categories were more meaningful than the actual measured values. Thus, the slope orientation was encoded using eight equal 45 categories, moving clockwise from north (centered on an azimuth of 0, thus with azimuths for this initial category ranging from 337.5 to 22.5), following the method of Qiu and Zhang [17]. The sine of the half slope orientation was used to quantify 
its value as the sine increase from 0 to 90 degree and then decrease from 90 to 180 degree. Pulsing the constant 1 was used to calibrate quantity of orientation. The vegetation cover was classified into five categories: 0 represents none, 1 represents very sparse, 2 represents sparse, 3 represents sparse to moderate, and 4 represents moderate to relatively dense. The slope, relative elevation above the nearest lake, and distance to the nearest lake were measured at each sample site (Table 1). And the tangent value was used to quantify the slope of dunes. All environmental variables were normalized before the multiple regressions.

\subsection{Solving Equations}

The multiple regressions between the parameters of the scaled gamma PDF and local environmental factors are as follows:

(a) Theoretical parameters. The theoretical value of the parameters of each profile is represented by values fitted using the least square fitting, denoted as $\mathrm{Y}$.

(b) The variables matrix are represented by the normalized environmental factors which were encoded by the specific rules mentioned above.

(c) The coefficients or the weights of these environmental factors are obtained by solving by the linear equations.

With the exception of fitting by least squares, the weights of the environmental factors for the parameters of $\lambda_{0}, \lambda_{1}, \lambda_{2}$ are fitted by two methods: based on the environmental factors of all profiles (FAP) and leave itself out or the factors of the other profiles (FOP). The former use the same weight vector for all 19 profiles, while the latter need 19 vectors to determine the parameters for each profile, respectively. Here, we use the mean, standard deviation (STD) and coefficient of variance (CV) to describe these weights calculated by the second method, as shown in Table 2. More details are listed in the Appendix (Tables A1-A3 correspond to $\lambda_{0}, \lambda_{1}$, and $\lambda_{2}$, respectively).

Table 2. The weight of environmental factors for parameters of soil moisture distribution.

\begin{tabular}{|c|c|c|c|c|c|c|c|c|}
\hline Para. & & $\begin{array}{l}\text { ing } \\
\text { hod }\end{array}$ & $\begin{array}{l}\text { Relative } \\
\text { Elev. (m) }\end{array}$ & $\begin{array}{c}\text { Dis. to } \\
\text { Lake (m) }\end{array}$ & $\begin{array}{l}\text { Dry Layers } \\
\text { (cm) }\end{array}$ & Slope $\left(^{\circ}\right)$ & Orientation & Vegetation \\
\hline \multirow{4}{*}{$\lambda_{0}$} & FAP & & 0.0531 & 0.0475 & 0.0010 & -0.1091 & -0.1664 & 1.9491 \\
\hline & & Average & 0.0493 & 0.0441 & 0.0010 & -0.1079 & -0.1666 & 1.9502 \\
\hline & FOP & STD & 0.0298 & 0.0435 & 0.0426 & 0.0290 & 0.0352 & 0.0331 \\
\hline & & $\mathrm{CV}$ & 0.6048 & 0.9849 & -43.59 & -0.2688 & -0.211 & 0.017 \\
\hline \multirow{4}{*}{$\lambda_{1}$} & FAP & & 0.0256 & 0.0091 & -0.0115 & 0.0547 & -0.0764 & 0.6018 \\
\hline & & Average & 0.0252 & 0.0070 & -0.0137 & 0.0548 & -0.0758 & 0.6021 \\
\hline & FOP & STD & 0.0302 & 0.0258 & 0.0235 & 0.0129 & 0.0224 & 0.0196 \\
\hline & & $\mathrm{CV}$ & 1.2016 & 3.6881 & -1.7105 & 0.2348 & -0.2959 & 0.0326 \\
\hline \multirow{4}{*}{$\lambda_{2}$} & FAP & & -0.0218 & 0.0068 & 0.0155 & -0.0203 & 0.0411 & -0.1638 \\
\hline & & Average & -0.0215 & 0.0076 & 0.0163 & -0.0199 & 0.0405 & -0.1639 \\
\hline & FOP & STD & 0.0129 & 0.0112 & 0.0086 & 0.0048 & 0.0090 & 0.0082 \\
\hline & & $\mathrm{CV}$ & -0.5980 & 1.4624 & 0.5260 & -0.2426 & 0.2222 & -0.0499 \\
\hline
\end{tabular}

Notes: parameters are fitted by two ways, based on the environmental factors of all profiles (FAP) and factors of the other profiles (FOP).

By comparing the weight vectors estimated by the two method above, we find that, generally, there is little difference between weights estimated by all profiles and the mean of weights by leave itself out. However, a larger CV is observed in the factor of relative elevation, distance to lake and thickness of dry layer, which are the sensitive factors affecting the soil moisture distribution based on detrended canonical correspondence analysis (DCCA) [12,13]. When the weights of the environmental factors are determined, the parameters of soil moisture distribution can be calculated by the encoded 
environmental variable matrix multiplying the weight vectors listed in Table 2 and Tables A1-A3. Table 3 presents parameters $\exp \left(\lambda_{0}-1\right), \lambda_{1}$ and $\lambda_{2}$ fitted by the three methods mentioned above.

Table 3. Parameters estimation of soil moisture distribution as a scaled PDF of gamma distribution through different fittings.

\begin{tabular}{cccccccccc}
\hline \multirow{2}{*}{ ID } & \multicolumn{3}{c}{ Best Fitted } & \multicolumn{3}{c}{ Fitted by All Profiles } & \multicolumn{3}{c}{ Fitted by Other 18 Profiles } \\
\cline { 2 - 10 } & $\mathbf{E x p}\left(\boldsymbol{\lambda}_{\mathbf{0}} \mathbf{- 1}\right)$ & $\boldsymbol{\lambda}_{\mathbf{1}}$ & $\boldsymbol{\lambda}_{\mathbf{2}}$ & $\mathbf{E x p}\left(\boldsymbol{\lambda}_{\mathbf{0}} \mathbf{- 1}\right)$ & $\boldsymbol{\lambda}_{\mathbf{1}}$ & $\boldsymbol{\lambda}_{\mathbf{2}}$ & $\mathbf{E x p}\left(\boldsymbol{\lambda}_{\mathbf{0}} \mathbf{- 1}\right)$ & $\boldsymbol{\lambda}_{\mathbf{1}}$ & $\boldsymbol{\lambda}_{\mathbf{2}}$ \\
\hline SA & 1.52 & 0.47 & -0.09 & 2.07 & 0.54 & -0.13 & 2.20 & 0.55 & -0.14 \\
SB & 2.61 & 1.24 & -0.45 & 1.83 & 0.81 & -0.22 & 1.31 & 0.53 & -0.06 \\
SC & 1.69 & 0.24 & 0.01 & 2.06 & 0.65 & -0.17 & 2.13 & 0.72 & -0.19 \\
SD & 1.56 & 0.47 & -0.10 & 1.93 & 0.50 & -0.13 & 2.01 & 0.50 & -0.14 \\
SE & 1.58 & 0.45 & -0.14 & 1.72 & 0.50 & -0.15 & 1.82 & 0.55 & -0.15 \\
SF & 1.19 & 0.66 & -0.09 & 1.79 & 0.82 & -0.20 & 2.47 & 1.00 & -0.34 \\
SH & 2.70 & 0.55 & -0.21 & 2.20 & 0.54 & -0.14 & 2.02 & 0.53 & -0.11 \\
SJ & 2.53 & 0.53 & -0.14 & 1.95 & 0.68 & -0.19 & 1.83 & 0.71 & -0.20 \\
SM & 1.89 & 0.54 & -0.13 & 1.98 & 0.64 & -0.19 & 2.16 & 0.82 & -0.31 \\
SN & 1.60 & 0.30 & -0.05 & 2.19 & 0.54 & -0.14 & 2.36 & 0.61 & -0.16 \\
SO & 2.69 & 1.17 & -0.42 & 1.96 & 0.62 & -0.17 & 1.84 & 0.53 & -0.13 \\
SP & 1.29 & 0.45 & -0.06 & 1.92 & 0.67 & -0.19 & 2.07 & 0.72 & -0.21 \\
SQ & 1.84 & 0.46 & -0.12 & 1.69 & 0.45 & -0.14 & 1.56 & 0.45 & -0.15 \\
ST & 2.69 & 0.66 & -0.21 & 2.01 & 0.53 & -0.14 & 1.88 & 0.51 & -0.12 \\
SU & 2.24 & 0.47 & -0.15 & 1.85 & 0.59 & -0.15 & 1.53 & 0.69 & -0.16 \\
SW & 2.35 & 0.80 & -0.20 & 2.22 & 0.50 & -0.13 & 2.16 & 0.37 & -0.09 \\
DS & 1.93 & 0.76 & -0.20 & 1.97 & 0.58 & -0.16 & 1.98 & 0.54 & -0.15 \\
ES & 1.84 & 0.53 & -0.18 & 1.84 & 0.63 & -0.19 & 1.84 & 0.68 & -0.20 \\
FS & 1.29 & 0.67 & -0.19 & 1.84 & 0.65 & -0.20 & 2.47 & 0.62 & -0.22 \\
\hline
\end{tabular}

\section{Simulation Results and Precision}

\subsection{Simulation Results}

On the basis of the input parameters for each profile shown in Table 3, the soil moisture profiles are estimated by substituting these parameters into the scaled gamma distribution PDF. Figure 4 presents the measured data and the simulated results based on best fitted method, calibrating parameters using all profiles' environmental factors and leaving itself out.

\subsection{Correlation Analysis}

Firstly, the correlation coefficients between measured data and simulated results are used to evaluate the performance of the entropy theory based model. The results are shown in Table 4 .

Theoretically, the best fitted results display a good linear correlation with the measured value. There are 13 profiles that show correlation coefficients larger than 0.9 , four profiles between 0.8 and 0.9 and two profiles about 0.7. As for the profiles of SC and SU, the least correlation between the measured and best gamma PDF fitted result, both profiles exhibit a substantial change of sand texture: a higher clay content appearing when the soil moisture increases again. Therefore, these scaled PDF are appropriate for about ninety five percent of the soil moisture profiles in the deep vadose zone of the Badian Jaran Desert, and the two exceptions are caused by the change of sand texture.

The correlation coefficients of the fitted results on the basis of local environmental factors from all 19 profiles perform well too: ten profiles showing larger than 0.9 , four profiles between 0.8 and 0.9 , two profiles between 0.75 and 0.8 , and three profiles between $0.56-0.75$. The results based on other 18 profiles are mostly close to those based on all nineteen profiles. Eight profiles displays correlation coefficients larger than 0.9 , four profiles between 0.8 and 0.9 , five profiles are about 0.7 or higher, and two profiles (SC and SU) between 0.5 and 0.7. Hence, the simulated results display a good correlation with the measured values. 
Table 4. Performance of the entropy based method under different fittings.

\begin{tabular}{cccccccccc}
\hline & \multicolumn{3}{c}{ Correlation Coefficient } & \multicolumn{7}{c}{ Relative Error } \\
\cline { 2 - 7 } ID & Best & By All & By Other & \multicolumn{2}{c}{ Best Fitted } & By All Profiles & By Other Profiles \\
\cline { 6 - 10 } & Fitted & Profiles & 18 Profiles & Mean & STD & Mean & STD & Mean & STD \\
\hline SA & 0.94 & 0.93 & 0.90 & $6.88 \%$ & $6.31 \%$ & $12.26 \%$ & $11.36 \%$ & $14.87 \%$ & $12.93 \%$ \\
SB & 0.97 & 0.95 & 0.93 & $13.69 \%$ & $13.57 \%$ & $18.53 \%$ & $35.86 \%$ & $23.14 \%$ & $25.99 \%$ \\
SC & 0.73 & 0.56 & 0.50 & $21.92 \%$ & $25.24 \%$ & $30.39 \%$ & $27.82 \%$ & $45.41 \%$ & $31.23 \%$ \\
SD & 0.91 & 0.87 & 0.83 & $9.43 \%$ & $7.26 \%$ & $23.08 \%$ & $10.96 \%$ & $28.53 \%$ & $14.42 \%$ \\
SE & 0.87 & 0.86 & 0.85 & $11.52 \%$ & $7.65 \%$ & $41.96 \%$ & $20.70 \%$ & $48.76 \%$ & $21.80 \%$ \\
SF & 0.94 & 0.90 & 0.85 & $9.92 \%$ & $8.36 \%$ & $14.83 \%$ & $18.01 \%$ & $16.83 \%$ & $21.54 \%$ \\
SH & 0.83 & 0.75 & 0.70 & $19.22 \%$ & $17.73 \%$ & $22.00 \%$ & $16.64 \%$ & $22.35 \%$ & $16.12 \%$ \\
SJ & 0.94 & 0.93 & 0.92 & $6.71 \%$ & $6.23 \%$ & $14.70 \%$ & $7.99 \%$ & $18.54 \%$ & $9.04 \%$ \\
SM & 0.91 & 0.90 & 0.90 & $10.12 \%$ & $8.18 \%$ & $12.25 \%$ & $9.26 \%$ & $12.06 \%$ & $9.93 \%$ \\
SN & 0.87 & 0.82 & 0.72 & $12.43 \%$ & $8.51 \%$ & $16.83 \%$ & $10.04 \%$ & $25.30 \%$ & $14.91 \%$ \\
SO & 0.90 & 0.76 & 0.68 & $17.89 \%$ & $14.62 \%$ & $27.99 \%$ & $15.16 \%$ & $28.86 \%$ & $15.56 \%$ \\
SP & 0.92 & 0.68 & 0.54 & $9.41 \%$ & $10.47 \%$ & $23.11 \%$ & $14.82 \%$ & $35.63 \%$ & $17.13 \%$ \\
SQ & 0.92 & 0.90 & 0.90 & $10.61 \%$ & $9.23 \%$ & $14.07 \%$ & $11.09 \%$ & $13.79 \%$ & $11.94 \%$ \\
ST & 0.91 & 0.90 & 0.90 & $10.61 \%$ & $7.49 \%$ & $13.97 \%$ & $9.51 \%$ & $12.90 \%$ & $11.01 \%$ \\
SU & 0.68 & 0.66 & 0.65 & $26.00 \%$ & $25.54 \%$ & $27.58 \%$ & $21.25 \%$ & $27.59 \%$ & $19.77 \%$ \\
SW & 0.95 & 0.94 & 0.94 & $9.03 \%$ & $7.46 \%$ & $12.78 \%$ & $7.77 \%$ & $17.82 \%$ & $7.60 \%$ \\
DS & 0.94 & 0.91 & 0.90 & $7.81 \%$ & $5.24 \%$ & $16.64 \%$ & $9.84 \%$ & $19.96 \%$ & $10.62 \%$ \\
ES & 0.84 & 0.80 & 0.77 & $12.62 \%$ & $11.16 \%$ & $30.13 \%$ & $16.47 \%$ & $39.92 \%$ & $20.07 \%$ \\
FS & 0.92 & 0.91 & 0.88 & $10.68 \%$ & $6.13 \%$ & $14.90 \%$ & $12.81 \%$ & $18.72 \%$ & $25.81 \%$ \\
\hline
\end{tabular}

\subsection{Error Analysis}

Similarly, the results of error analysis are shown in Table 4 too. The relative error is used to quantify the performance of the simulated results. Firstly, the best fitted results display a small error between the simulated and measured values. The average relative errors are less than 0.15 in fifteen profiles, and four profiles are between 0.15 and 0.3 . This indicates this method can provide good precision for most of the soil moisture profiles.

The fitted results based on local environmental factors also perform well. Most of the relative errors are less than $30 \%$ and the maximum average error is less than $50 \%$ in a profile, although several profiles showing a good correlation coefficients exhibit a high relative error, such as SE, SP and ES. In the top ten meter depth zone of desert regions, this precision is acceptable on the basis of local environmental factors instead of drilling samples and drying them.

By comparison the errors based on parameters estimated by two methods, we find the model performs a little better when parameters determined by all the profiles' environmental factors than fitted by leave itself out. The reason is the former counts in the autocorrelation, and the latter is more objective as the validation is performed on data that were not used in the calibration. Hence, we concentrate more on discussing the errors from the second method and analyzing the main driving factors.

Generally, the performance of the model calibrated by the last method deliver an acceptable accuracy although the error might be close to $50 \%$ in a couple of profiles. Nine profiles show a high accuracy with errors less than $20 \%$, six profiles showing a middle level with errors between $20 \%$ and $30 \%$, and poor performance $(30 \%-40 \%)$ is seen in four profiles, including SC, SE, SP and ES. From the estimated parameters of the profiles in which the model performs poorly, we can find that: (1) the reason for SC is the change of soil texture with more clay content that leads to the soil moisture pattern not be consistent with that of the gamma distribution; (2) SE, SP and ES, however, are able to show good precision when fitted appropriately; (3) profile SE exhibits a good CC but a large relative error. This means the parameters for $\lambda_{1}$ and $\lambda_{2}$ are estimated appropriately, while $\lambda_{0}$, the factor to scale the PDF, is higher than the real value; (4) as for ES, the middle level CC indicates the error is not caused by $\lambda_{0}$ alone, and actually the reason is mainly due to a larger $\lambda_{1}$ from Table 3; (5) finally, 
the estimated three parameters of SP are different from the best fitted value: a larger value for $\lambda_{0}, \lambda_{1}$, and smaller for $\lambda_{2}$. This means the estimated soil moisture concentrates more around the mode than the measured profile. Combined our previous studies based on detrended canonical correspondence analysis (DCCA), the dominating factor is thickness of the dry sand layer near the surface for SE and ES, and distance to lake for SP, respectively $[12,13]$. Compared with the other environmental factors, the thickness of the dry sand near the surface can be affected by small intensity precipitation, which might lead to the model performing poorly in some profiles. For SP, it is located near a lake that has dried up, and the measured distance is to another lake located beyond the divide line of the dried lake.

\subsection{Applicability of the Model}

This method performs well on estimating soil moisture distribution in most profiles with the exception of several profiles caused by abrupt change of texture, such as SC and SU, in the study area, the Badain Jaran Desert of northwestern China. In order to simulate the soil moisture profiles based on local land surface factors instead of sampling sand vertically, three requirements should be met.

The first is the soil moisture distribution can be considered as stable in a specific period. Here, the soil moisture distribution at the top ten meter zone of the desert region meets the first requirement since the soil water moves at a very low flow rate (about $1 \mathrm{~cm} /$ year) and the ten meter depth sand profile represents a one thousand year recharge record. The former indicates the shape of the soil moisture profile is almost a constant, so the geometric mean of the profile can be considered as a constant. The latter indicates that the arithmetic mean is a constant as the average recharge rate is a constant at a one thousand year scale. Hence, the two limitations, both constant in arithmetic mean and geometric mean, are necessary to determine patterns of soil moisture distribution.

The second requirement is a gradual change of soil texture and soil moisture. As presented in the text above, the abrupt change of texture will lead to the model performing poorly in these profiles like SC and SU. The reason is the trend of the PDF of the gamma distribution decreases monotonously after the mode. In the desert region, fortunately, most of the soil moisture profiles exhibit the same trend which enables the applicability of this method in the desert regions.

Another requirement is determining the weight vector of the environmental factors based on sufficient measured soil moisture profiles. In this study, nineteen soil moisture profiles are used to calibrate the parameters by the application of fuzzy mathematics. In a desert region, the influence of rainfall on soil moisture is mostly small in a short period, hence the relationships can be established simply by the linear equations.

In other regions, however, the soil moisture distribution is not static. For example, in humid climatic conditions, the vertical soil moisture distribution varies substantially on a daily scale or even an hourly scale. The reason is the much more intensive and frequent precipitation will lead to the temporal and spatial patterns of soil moisture varying substantially. On the contrary, the soil moisture distribution is determined mainly by the long term climatic conditions, and the precipitation events have little effect on soil moisture distribution in the deep vadose zone of desert regions at a daily or monthly scale. Therefore, the assumption of static state is appropriate for the arid desert regions while it is challenged in humid regions.

\section{Conclusions}

From the establishment of the model based on information entropy, parameter determination and precision tests, the conclusions of this work are as follows:

1. The soil moisture distribution curve can be described as a scaled PDF in the deep vadose zone of the Badian Jaran Desert. The function is solved by PME with the constraint of normalization, known arithmetic mean and geometric mean, and the soil moisture vertical distribution curve is a scaled PDF of gamma distribution with a general form as $f(z)=e^{\lambda_{0}-1} e^{\lambda_{1} z} z^{\lambda_{2}}$. 
2. The parameters of soil moisture distribution are estimated by local land surface environmental factors like terrain and vegetation: the theoretic parameters are estimated by least squares fitting, then the linear equations were used to describe the relationship between environmental factors and best fitted parameters. The coefficients of the environmental factors are obtained by solving these equations.

3. The simulated results show a good correlation and an acceptable precision with the measured values. The correlation coefficient is larger than 0.9 in more than a half profiles and most are over 0.8 ; the relative errors are smaller than $30 \%$ in most of the profiles and it can less than $15 \%$ when fitted by appropriate parameters.

Therefore, a simple alternative method is established to estimate the soil moisture distribution in the deep vadose zone of desert regions based on the local land surface environmental factors, and this method would be useful since these environmental factors can be obtained by remote sensing data. Meanwhile, we should bear in mind that this method is applicable in desert regions but challenged in humid and semi-humid regions. The reason is the former is determined mainly by the long term climatic conditions and local environmental factors, while the latter is determined by the short term climatic conditions, especially more intensive and frequent precipitation.

Acknowledgments: This work was supported by Major State Basic Research Development Program of China (No.2013CB035905) and China Postdoctoral Science Foundation (NO 2016M592671).

Author Contributions: Xiangyang Zhou, the first author, was responsible for developing the mathematical formulation and establishing the model, error analysis and writing of this paper. Wenjuan Lei as the corresponding author proposed the idea of this study, and searched the background of entropy theory simulating soil moisture distribution. Jinzhu Ma provided the measured soil moisture data and the local environmental factors to test the performance of this model, and helped to revise this manuscript. All authors have read and approved the final manuscript.

Conflicts of Interest: The authors declare no conflict of interest.

\section{Appendix A}

Table A1. The weights of local environmental factors for parameter $\lambda_{0}$, represented by $\exp \left(\lambda_{0}-1\right)$.

\begin{tabular}{ccccccc}
\hline ID & $\begin{array}{c}\text { Relative } \\
\text { Elevation }(\mathbf{m})\end{array}$ & $\begin{array}{c}\text { Distance to } \\
\text { Lake }(\mathbf{m})\end{array}$ & $\begin{array}{c}\text { Dry Layers } \\
\mathbf{( \mathbf { c m } )}\end{array}$ & Slope $\left.\mathbf{(}^{\circ}\right)$ & Orientation & Vegetation \\
\hline FAP & 0.0531 & 0.0475 & 0.0010 & -0.1091 & -0.1664 & 1.9491 \\
SA & 0.0520 & -0.0102 & 0.0062 & -0.1286 & -0.2471 & 1.9979 \\
SB & -0.0413 & -0.0275 & -0.0248 & -0.1408 & -0.1378 & 1.9069 \\
SC & 0.0181 & 0.0970 & 0.0195 & -0.1220 & -0.1801 & 1.9844 \\
SD & 0.0497 & 0.1112 & -0.0308 & -0.0938 & -0.1626 & 1.9844 \\
SE & 0.0594 & -0.0177 & -0.1398 & -0.1334 & -0.1965 & 1.9986 \\
SF & 0.0058 & 0.0511 & 0.0882 & -0.1595 & -0.0796 & 1.9954 \\
SH & 0.0668 & 0.1236 & -0.0033 & -0.0714 & -0.1533 & 1.9004 \\
SJ & 0.0343 & -0.0373 & -0.0299 & -0.0591 & -0.2287 & 1.9105 \\
SM & 0.0787 & 0.0587 & -0.0007 & -0.1286 & -0.1701 & 1.9315 \\
SN & 0.0398 & 0.0460 & 0.0083 & -0.1082 & -0.1843 & 1.9418 \\
SO & 0.0778 & 0.0958 & 0.0609 & -0.0831 & -0.1498 & 1.9041 \\
SP & 0.0845 & 0.0313 & 0.0124 & -0.1248 & -0.1552 & 1.9871 \\
SQ & 0.0586 & 0.0444 & -0.0017 & -0.1058 & -0.1757 & 1.9426 \\
ST & 0.0838 & 0.0628 & -0.0050 & -0.1118 & -0.1182 & 1.9146 \\
SU & 0.0518 & 0.0482 & -0.0007 & -0.1093 & -0.1646 & 1.9480 \\
SW & 0.0713 & 0.0313 & 0.0176 & -0.1136 & -0.1543 & 1.9335 \\
DS & 0.0546 & 0.0463 & 0.0013 & -0.1081 & -0.1675 & 1.9507 \\
ES & 0.0558 & 0.0466 & 0.0025 & -0.1137 & -0.1622 & 1.9529 \\
FS & 0.0316 & 0.0337 & -0.0007 & -0.0329 & -0.1784 & 1.9689 \\
Average & 0.0493 & 0.0441 & -0.0010 & -0.1079 & -0.1666 & 1.9502 \\
STD & 0.0298 & 0.0435 & 0.0426 & 0.0290 & 0.0352 & 0.0331 \\
CV & 0.6048 & 0.9849 & -43.5917 & -0.2688 & -0.2110 & 0.0170 \\
\hline
\end{tabular}


Table A2. The weight of local environmental factors for parameter $\lambda_{1}$.

\begin{tabular}{ccccccc}
\hline ID & $\begin{array}{c}\text { Relative } \\
\text { Elevation }(\mathbf{m})\end{array}$ & $\begin{array}{c}\text { Distance to } \\
\text { Lake }(\mathbf{m})\end{array}$ & $\begin{array}{c}\text { Dry Layers } \\
\mathbf{( \mathbf { c m } )}\end{array}$ & Slope $\left.\mathbf{(}^{\circ}\right)$ & Orientation & Vegetation \\
\hline FAP & 0.0256 & 0.0091 & -0.0115 & 0.0547 & -0.0764 & 0.6018 \\
SA & 0.0253 & -0.0051 & -0.0103 & 0.0499 & -0.0963 & 0.6139 \\
SB & -0.0847 & -0.0785 & -0.0416 & 0.0177 & -0.0430 & 0.5526 \\
SC & -0.0010 & 0.0467 & 0.0025 & 0.0449 & -0.0868 & 0.6286 \\
SD & 0.0243 & 0.0340 & -0.0240 & 0.0607 & -0.0749 & 0.6156 \\
SE & 0.0278 & -0.0139 & -0.0613 & 0.0461 & -0.0871 & 0.6193 \\
SF & 0.0485 & 0.0074 & -0.0538 & 0.0791 & -0.1185 & 0.5794 \\
SH & 0.0258 & 0.0103 & -0.0116 & 0.0553 & -0.0762 & 0.6011 \\
SJ & 0.0260 & 0.0110 & -0.0108 & 0.0536 & -0.0750 & 0.6027 \\
SM & 0.0238 & 0.0083 & -0.0114 & 0.0560 & -0.0762 & 0.6030 \\
SN & 0.0750 & 0.0145 & -0.0388 & 0.0510 & -0.0100 & 0.6287 \\
SO & 0.0475 & 0.0520 & 0.0415 & 0.0778 & -0.0617 & 0.5621 \\
SP & 0.0319 & 0.0058 & -0.0092 & 0.0515 & -0.0742 & 0.6096 \\
SQ & 0.0238 & 0.0101 & -0.0107 & 0.0536 & -0.0734 & 0.6039 \\
ST & 0.0264 & 0.0095 & -0.0117 & 0.0546 & -0.0751 & 0.6009 \\
SU & 0.0538 & -0.0070 & 0.0249 & 0.0571 & -0.1127 & 0.6237 \\
SW & 0.0383 & -0.0022 & 0.0001 & 0.0516 & -0.0680 & 0.5910 \\
DS & 0.0204 & 0.0129 & -0.0125 & 0.0512 & -0.0726 & 0.5962 \\
ES & 0.0249 & 0.0093 & -0.0119 & 0.0558 & -0.0775 & 0.6009 \\
FS & 0.0202 & 0.0057 & -0.0120 & 0.0737 & -0.0794 & 0.6068 \\
Average & 0.0252 & 0.0070 & -0.0137 & 0.0548 & -0.0758 & 0.6021 \\
STD & 0.0302 & 0.0258 & 0.0235 & 0.0129 & 0.0224 & 0.0196 \\
CV & 1.2016 & 3.6881 & -1.7105 & 0.2348 & -0.2959 & 0.0326 \\
\hline
\end{tabular}

Table A3. The weight of local environmental factors for parameter $\lambda_{2}$.

\begin{tabular}{ccccccc}
\hline ID & $\begin{array}{c}\text { Relative } \\
\text { Elevation }(\mathbf{m})\end{array}$ & $\begin{array}{c}\text { Distance to } \\
\text { Lake }(\mathbf{m})\end{array}$ & $\begin{array}{c}\text { Dry Layers } \\
(\mathbf{c m})\end{array}$ & Slope $\left.\mathbf{(}^{\circ}\right)$ & Orientation & Vegetation \\
\hline FAP & 0.0531 & 0.0475 & 0.0010 & -0.1091 & -0.1664 & 1.9491 \\
SA & 0.0520 & -0.0102 & 0.0062 & -0.1286 & -0.2471 & 1.9979 \\
SB & -0.0413 & -0.0275 & -0.0248 & -0.1408 & -0.1378 & 1.9069 \\
SC & 0.0181 & 0.0970 & 0.0195 & -0.1220 & -0.1801 & 1.9844 \\
SD & 0.0497 & 0.1112 & -0.0308 & -0.0938 & -0.1626 & 1.9844 \\
SE & 0.0594 & -0.0177 & -0.1398 & -0.1334 & -0.1965 & 1.9986 \\
SF & 0.0058 & 0.0511 & 0.0882 & -0.1595 & -0.0796 & 1.9954 \\
SH & 0.0668 & 0.1236 & -0.0033 & -0.0714 & -0.1533 & 1.9004 \\
SJ & 0.0343 & -0.0373 & -0.0299 & -0.0591 & -0.2287 & 1.9105 \\
SM & 0.0787 & 0.0587 & -0.0007 & -0.1286 & -0.1701 & 1.9315 \\
SN & 0.0398 & 0.0460 & 0.0083 & -0.1082 & -0.1843 & 1.9418 \\
SO & 0.0778 & 0.0958 & 0.0609 & -0.0831 & -0.1498 & 1.9041 \\
SP & 0.0845 & 0.0313 & 0.0124 & -0.1248 & -0.1552 & 1.9871 \\
SQ & 0.0586 & 0.0444 & -0.0017 & -0.1058 & -0.1757 & 1.9426 \\
ST & 0.0838 & 0.0628 & -0.0050 & -0.1118 & -0.1182 & 1.9146 \\
SU & 0.0518 & 0.0482 & -0.0007 & -0.1093 & -0.1646 & 1.9480 \\
SW & 0.0713 & 0.0313 & 0.0176 & -0.1136 & -0.1543 & 1.9335 \\
DS & 0.0546 & 0.0463 & 0.0013 & -0.1081 & -0.1675 & 1.9507 \\
ES & 0.0558 & 0.0466 & 0.0025 & -0.1137 & -0.1622 & 1.9529 \\
FS & 0.0316 & 0.0337 & -0.0007 & -0.0329 & -0.1784 & 1.9689 \\
Average & 0.0493 & 0.0441 & -0.0010 & -0.1079 & -0.1666 & 1.9502 \\
STD & 0.0298 & 0.0435 & 0.0426 & 0.0290 & 0.0352 & 0.0331 \\
CV & 0.6048 & 0.9849 & -43.5917 & -0.2688 & -0.2110 & 0.0170 \\
\hline
\end{tabular}

\section{References}

1. Western, A.W.; Grayson, R.B.; Blöschl, G.; Willgoose, G.R.; McMahon, T.A. Observed spatial organization of soil moisture and its relation to terrain indices. Water Resour. Res. 1999, 35, 797-810. [CrossRef]

2. Western, A.W.; Blöschl, G. On the spatial scaling of soil moisture. J. Hydrol. 1999, 217, 203-224. [CrossRef] 
3. Eltahir, E.A. A soil moisture-Rainfall feedback mechanism: 1. Theory and observations. Water Resour. Res. 1998, 34, 765-776. [CrossRef]

4. Nash, J.E.; Sutcliffe, J.V. River flow forecasting through conceptual models part I, a discussion of principles. J. Hydrol. 1970, 10, 282-290. [CrossRef]

5. Nash, M.S.; Wierenga, P.J.; Gutjahr, A. Time series analysis of soil moisture and rainfall along a line transect in arid rangeland. Soil Sci. 1991, 152, 189-198. [CrossRef]

6. Ulaby, F.T.; Dubois, P.C.; van Zyl, J. Radar mapping of surface soil moisture. J. Hydrol. 1996, 184, 57-84. [CrossRef]

7. Pachepsky, Y.; Guber, A.; Jacques, D.; Simunek, J.; van Genuchten, M.T.; Nicholson, T.; Cady, R. Information content and complexity of simulated soil water fluxes. Geoderma 2006, 134, 253-266. [CrossRef]

8. Al-Hamdan, O.Z.; Cruise, J.F. Soil moisture profile development from surface observations by principle of maximum entropy. J. Hydrol. Eng. 2010, 15, 327-337. [CrossRef]

9. Singh, V.P. Entropy theory for derivation of infiltration equations. Water Resour. Res. 2010, 46, W03527. [CrossRef]

10. Singh, V.P. Entropy theory for movement of moisture in soils. Water Resour. Res. 2010, 46, W03516. [CrossRef]

11. Mishra, V.; Ellenburg, W.L.; Al-Hamdan, O.Z.; Bruce, J.; Cruise, J.F. Modeling Soil Moisture Profiles in Irrigated Fields by the Principle of Maximum Entropy. Entropy 2015, 17, 4454-4484. [CrossRef]

12. Ma, J.Z.; Zhou, X.Y.; Wang, Y.Q.; Gates, J.B. Spatial distribution of soil moisture at unsaturated zone in megadunes, southeast of Badain Jaran Desert. J. Desert Res. 2011, 31, 1365-1372.

13. Pan, F.; Ma, J.; Zhou, X.; Edmunds, W.M.; Gates, J.B. Erratum to: Geostatistical characterization of soil moisture and chloride distribution in deep vadose profiles of the Badain Jaran Desert, Northwestern China. Environ. Earth Sci. 2013, 70, 2423. [CrossRef]

14. Cook, P.G.; Edmunds, W.M.; Gaye, C.B. Estimating paleorecharge and paleoclimate from unsaturated zone profiles. Water Resour. Res. 1992, 28, 2721-2731. [CrossRef]

15. Edmunds, W.; Tyler, S. Unsaturated zones as archives of past climates: toward a new proxy for continental regions. Hydrogeol. J. 2002, 10, 216-228. [CrossRef]

16. Ma, J.; Li, D.; Zhang, J.; Edmunds, W.M.; Prudhomme, C. Groundwater recharge and climatic change during the last 1000 years from unsaturated zone of SE Badain Jaran Desert. Chin. Sci. Bull. 2003, 48, 1469-1474. [CrossRef]

17. Qiu, Y.; Zhang, J. The ordination axes clustering based on detrended canonical correspondence analysis ordination and its application to the analysis of the ecological gradients of plant communities in Bashuigou catchment, Guandi Mountain. Acta Ecol. Sin. 2000, 20, 199-206.

18. Yan, M.C.; Wang, G.Q.; Li, B.S.; Dong, G.R. Formation and growth of high megadunes in Badain Jaran Desert. Acta. Geogr. Sin. 2001, 56, 83-91.

19. Ma, J.; Edmunds, W.M. Groundwater and lake evolution in the Badain Jaran Desert ecosystem, Inner Mongolia. Hydrogeol. J. 2006, 14, 1231-1243. [CrossRef]

20. Domrös, M.; P'eng, G. The Climate of China; Springer-Verlag: Berlin, Germany, 1988.

21. Shannon, C.E. A mathematical theory of communications, I and II, Bell Syst. Tech. J. 1948, 27, $379-423$.

22. Jaynes, E.T. Information theory and statistical mechanics. II. Phys. Rev. 1957, 108, 171-190. [CrossRef]

23. Jaynes, E.T. Information theory and statistical mechanics. Phys. Rev. 1957, 106, 620-630. [CrossRef]

24. Conrad, K. Probability Distributions and Maximum Entropy. Available online: http://www.math.uconn. edu/ kconrad/blurbs/analysis/entropypost.pdf (accessed on 27 August 2016).

25. Gates, J.B.; Edmunds, W.M.; Darling, W.G.; Ma, J.; Pang, Z.; Young, A.A. Conceptual model of recharge to southeastern Badain Jaran Desert groundwater and lakes from environmental tracers. Appl. Geochem. 2008, 23, 3519-3534. [CrossRef]

26. Ma, J.; Edmunds, W.M.; He, J.; Jia, B. A 2000 year geochemical record of palaeoclimate and hydrology derived from dune sand moisture. Paleogeogr. Palaeoclimatol. Palaeoecol. 2009, 276, 38-46. [CrossRef]

27. Ma, J.; Wang, Y.; Zhao, X.; Jin, X.; Ning, N.; Edmunds, W.M.; Zhou, X. Spatial distribution of chloride and nitrate within an unsaturated dune sand of a cold-arid desert: Implications for paleoenvironmental records. Catena 2012, 96, 68-75. [CrossRef] 